\title{
A Study of Foreign Exchange Exposure in the Indian IT Sector
}

\author{
Mihir Dash* and Manoj Yadav ${ }^{\dagger}$
}

\section{Abstract}

Foreign exchange exposure measures the extent of fluctuation of a firm's future cash flows with respect to exchange rate movements. In particular, such fluctuation can have an adverse impact on firms which are already under tight liquidity constraints, often leading to financial distress. Thus, firms must evaluate their foreign exchange exposure in order to effectively hedge their foreign exchange risk.

This study examines the issue of foreign exchange rate exposure in the Indian information technology (IT) sector. Foreign exchange exposure is particularly important for firms in the Indian IT sector, as a major part of their revenue is derived from exports. Dash and Madhava (2009) found positive foreign exchange exposure for the sector in the period 2005-07, and alarmingly high level of exposure for some small-cap IT companies.

Since then, in the aftermath of the global financial crisis, the nature of the IT sector has dramatically changed, with lower dependence on the US market in particular. The present study assesses whether there is still significant positive foreign exchange exposure in the Indian IT sector, and whether there is still a significant difference in foreign exchange exposure between large-cap, mediumcap, and small-cap IT firms. The study was based on a

* Alliance University, Bangalore, India; mihirda@rediffmail.com † Alliance University, Bangalore, India; 
sample of thirty Indian IT firms for the period 2009-12. The foreign exchange exposure of the sample firms was computed using the Bodnar-Marston (2002) formula. The hypotheses were tested using t-tests and dummy variable regression.

The results of the study indicate significant positive foreign exchange exposure in the Indian IT sector, and decreasing foreign exchange exposure across large-cap, medium-cap, and small-cap IT firms, according to operational scale. The results also indicate a negative impact of foreign exchange exposure on profitability, with positive impact for large-cap IT firms. Thus, downward movements in the exchange rate would benefit small- and mid-cap IT firms but would adversely affect large-cap firms, and vice versa for upward movements.

Keywords: foreign exchange exposure, foreign exchange risk, Indian IT sector.

\section{Introduction}

In this age of globalization, every company is looking to tap into the international market, with increasing emphasis on global sourcing and delivery. Multinational firms may operate in several different countries, and thus their operations involve multiple foreign currencies. In this context, exchange rate fluctuation has emerged as a very real problem. The three types of exposure that multinational firms face are: transaction exposure, translation exposure, and economic exposure.

Transaction exposure refers to change in the value of cash flows that may arise due to unexpected changes in the exchange rate. It measures the sensitivity of the home currency value of cash inflows and outflows in foreign currency to unanticipated changes in exchange rates. A firm is subject to transaction exposure when it has monetary items whose value are contractually fixed in foreign currencies and do not change with the exchange rate.

Transaction exposure also arises when a firm borrows or lends in a foreign currency. For instance, consider a firm in India that borrows US\$ 1 million from a firm in New York for three months. During a period if the dollar appreciates against the Indian rupee 
the borrower will have a greater burden in terms of rupees. The reverse takes place when the dollar depreciates.

Translation exposure arises when a firm has assets and/or liabilities denominated in foreign currency which need to be translated in books of accounts in the domestic currency for accounting purposes. This is also known as accounting exposure as it relates only to book values of the concerned assets and/or liabilities; in this case, there is no actual conversion of currencies, as no cash transactions take place.

Economic or operating exposure is the effect of unexpected changes in exchange rates on the firm's future operating cash flows. Such a change in the exchange rate may affect the firm's future cash flows directly through its revenues and costs, and indirectly through its impact on the firm's competitiveness by affecting its consumers and competitors.

The major portion of business of Indian IT firms takes place in foreign countries, particularly the U.S. According to NASSCOM President Som Mittal, “...rupee depreciation helps us in the long term because it ensures competitiveness for the industry. But in the short run, we do not really gain because as an industry we do not want currency movement to be in the centre of loss or profit, because most people want to get what they have projected in terms of pricing." $\ddagger$ In particular, experts suggest that a $1 \%$ depreciation in the rupee has a positive impact of about 25-40 basis points on the margins of IT companies. A depreciating rupee helps IT companies improve their margins as they earn revenues in foreign currency, but sudden fluctuations hamper the planning process for companies and increase a company's exposure to financial risk and drastically minimize savings. Sharp fluctuations in the exchange rates hit the small- and mid- cap companies harder than for large companies in their profitability.

‡ http://m.firstbiz.firstpost.com/economy/not-much-gains-from-fallingre-in-short-term-nasscom-30091.html 


\section{Literature Review}

Foreign exchange exposure measures the extent of fluctuation of a firm's future cash flows with respect to exchange rate movements. Foreign exchange exposure is a significant risk factor for firms engaged in international business. Jorion (1990) has observed that the volatility of exchange rates is substantially higher than that of interest rates or of inflation. However, as it is difficult to directly measure future cash flows, researchers have generally examined foreign exchange exposure by examining how the firm's market value responds to changes in exchange rates.

Several studies have empirically addressed the issue of foreign exchange rate exposure, particularly for U.S. firms (e.g. Jorion, 1990; Bodnar and Gentry, 1993; Amihud, 1994; Choi and Prasad, 1995; Griffin and Stulz, 1997; Allayannis, 1997). The studies generally reported negligibly low levels of foreign exchange exposure for most firms, even for firms with significant foreign operations.

Jorion (1990) proposed a regression methodology for measuring exchange rate exposure at firm level, taking stock returns as the dependent variable, and rate of change of weighted exchange rate and market returns as the independent variables. He found very weak support for exchange rate exposure, but significant crosssectional differences in the exposure of U.S. multinationals. On the other hand, Bodnar and Gentry (1993) examined industry-level exposures in U.S., Canada, and Japan, and found significant exposure for some industries in all three countries. Choi and Prasad (1995) examined the exchange risk sensitivity of U.S. multinational firms in the period 1978-89, and reported that exchange rate fluctuations affected firm value. They also found that differences in exchange risk sensitivity were related to firm-specific variables such as sales and assets.

Bodnar and Marston (2002) developed a model of foreign exchange exposure dependent on only three variables - the percentage of the firm's revenues and expenses denominated in foreign currency and its profit rate. They suggested that the low levels of exposure found by previous empirical studies may be due to operational hedges, 
wherein multinational firms match their foreign currency revenues and costs.

Salifu et al (2007) analyzed the foreign exchange risk exposure of the firms listed in Ghana with respect to Cedi to USD, GBP, Euro, and a weighted exchange rate index. They found that foreign exchange exposure was highest against USD (55\%), followed by GBP (35\%), and Euro (10\%). El-Masry et al (2007) studied the foreign exchange exposure of non-financial UK firms with respect to their size and foreign operations. They found evidence of significant foreign exchange exposure, with higher impact on larger firms as compared to small and medium firms, and higher impact on firms with higher foreign exchange revenue.

Hyde (2007) analyzed the response of stock returns at the industry level to market, interest rate, and exchange rate risk in France, Germany, Italy and United Kingdom, and found significant level of risk exposure in all major four economies, but with different beta coefficients in different countries. Dash and Madhava (2009) analyzed the foreign exchange exposure of the Indian IT sector in the period 2005-07. They found that foreign exchange exposure was alarmingly high for a small fraction of small-cap IT firms, while the mid-cap and large-cap IT firms had relatively low/moderate exposure levels, with the majority of large-cap IT firms having already hedged their foreign exchange risk.

Dhasmana (2013) studied the factors affecting exchange rate exposure and the effects of exchange rate exposure for Indian firms over the period 1995-2011 using the Bodnar-Marston (2002) model. He found that exchange rate volatility has a significant impact on foreign exchange exposure, apart from firm-specific factors such as firm size and growth. On the other hand, he found that foreign exchange exposure had significant impact on output growth, earnings per share, and capital expenditures of the firms, perhaps moderated by the nature of the exchange rate regime. The literature on foreign exchange exposure is very diffuse and primary focused on U.S. firms. Further, the findings on foreign exchange exposure seem to vary with industry and with country.

Foreign exchange exposure is particularly important for firms in the Indian IT sector, as a major part of their revenue is derived 
from exports. Dash and Madhava (2009) had found positive foreign exchange exposure for the sector in the period 2005-07, and alarmingly high level of exposure for some small-cap IT companies. Since then, in the aftermath of the global financial crisis, the nature of the IT sector has dramatically changed, with lower dependence on the US market in particular. The present study addresses the issue of foreign exchange exposure in the Indian IT sector and its impact on the profitability across large-cap, medium-cap, and small-cap IT firms.

\section{Methodology}

The primary objectives of the study are to measure the level of foreign exchange exposure of IT firms, and to identify the impact of foreign exchange exposure on profitability of IT firms. The present study assesses whether there is still significant positive foreign exchange exposure in the Indian IT sector, whether there is still a significant difference in foreign exchange exposure between largecap, medium-cap, and small-cap IT firms, and whether foreign exchange exposure has an impact on the profitability of IT companies.

The data for the study consists of secondary data collected from the Capitaline database. The research period selected for the study is 2009-12. The sample consists of thirty Indian IT firms having global operations which consist of large, mid and small cap categories, as detailed in the table below. The sample was a judgmental sample, selected based on data availability.

\begin{tabular}{|l|l|l|}
\hline small-cap companies & mid-cap companies & large-cap companies \\
\hline Thinksoft & Genesys Intl. Corp & Infosys \\
\hline Geodesic Ltd & Infinite computers & TCS \\
\hline Subex Ltd & $\begin{array}{l}\text { Omnitech Info Solutions } \\
\text { Ltd }\end{array}$ & HCL \\
\hline Saksoft Ltd & $\begin{array}{l}\text { Nucleus Software Exports } \\
\text { Ltd }\end{array}$ & Tech Mahindra \\
\hline $\begin{array}{l}\text { ASM Technologies } \\
\text { Ltd }\end{array}$ & Geometric Ltd & Wipro \\
\hline
\end{tabular}




\begin{tabular}{|c|c|c|}
\hline small-cap companies & mid-cap companies & large-cap companies \\
\hline $\begin{array}{l}\text { Glodyne Technoserve } \\
\text { Ltd }\end{array}$ & Sonata Software Ltd & $\begin{array}{l}\text { Polaris Financial } \\
\text { Technology Ltd }\end{array}$ \\
\hline $\begin{array}{l}\text { Goldstone } \\
\text { Technologies Ltd }\end{array}$ & Hinduja Global Solution & NIIT Technologies Ltd \\
\hline $\begin{array}{l}\text { Info-Drive Software } \\
\text { Ltd }\end{array}$ & TATA Elxis & $\begin{array}{l}\text { Hexaware Technologies } \\
\text { Ltd }\end{array}$ \\
\hline $\begin{array}{l}\text { Logix Microsystem } \\
\text { Ltd }\end{array}$ & $\begin{array}{l}\text { Sasken Communication } \\
\text { Technologies }\end{array}$ & Mindtree \\
\hline \multirow[t]{2}{*}{$\begin{array}{l}\text { Allied Digital } \\
\text { Services Ltd }\end{array}$} & & Mphasis \\
\hline & & Infotech Enterprises Ltd \\
\hline
\end{tabular}

The foreign exchange exposure of the sample IT firms was measured using the Bodnar-Marston (2002) formula $F E=h_{1}+\left(h_{2}-h_{1}\right) *(1 / r-1)$, where $\mathrm{h}_{1}$ represents the ratio of foreign exchange revenue to total revenue, $h_{2}$ represents the ratio of foreign exchange expenditure to total expenditure, and $r$ represents the profit rate. The profitability of the sample IT firms was measured using the adjusted profit after tax margin (APATM) and the return on capital employed (ROCE). The hypotheses were tested using t-tests and dummy variable regression.

\section{Findings}

The descriptive statistics of foreign exchange exposure in the sample IT companies across the research period is presented in Table 1.

Table 1: descriptive statistics of foreign exchange exposure

\begin{tabular}{|c|c|c|c|c|}
\hline year & Mean & Std. Dev. & t Stat & p-value \\
\hline $2009-10$ & 0.3243 & 0.1729 & 10.2772 & 0.0000 \\
\hline $2010-11$ & 0.2835 & 0.1622 & 9.5762 & 0.0000 \\
\hline $2011-12$ & 0.2630 & 0.1632 & 8.8264 & 0.0000 \\
\hline
\end{tabular}

The foreign exchange exposure of the sample IT companies varied considerably, from a minimum of 0.0023 to a maximum level of 
1.0527, and was found to be positive and significant across the research period. Further, there was found to be a significant decrease in foreign exchange exposure from 2009-10 to 2010-11 [ $\mathrm{t}=$ -2.134, $\mathrm{p}=0.0205]$, but not significant from 2010-11 to 2011-12 [ $\mathrm{t}=$ $1.030, \mathrm{p}=0.1560]$.

The foreign exchange exposure of small-cap, mid-cap, and largecap IT companies across the research period is presented in Tables 2-4.

Table 2: foreign exchange exposure for the year 2009-10

\begin{tabular}{|l|l|l|}
\hline Large-cap & Mean & 0.4377 \\
\hline & Std. Dev. & 0.1344 \\
\hline Medium-cap & Mean & 0.3220 \\
\hline & Std. Dev. & 0.0862 \\
\hline Small-cap & Mean & 0.2017 \\
\hline & Std. Dev. & 0.1928 \\
\hline
\end{tabular}

F Stat $=6.857, \mathrm{p}=0.0000$

Table 3; foreign exchange exposure for the year 2010-11

\begin{tabular}{|l|l|c|}
\hline Large-cap & Mean & 0.3964 \\
\hline & Std. Dev. & 0.1451 \\
\hline Medium-cap & Mean & 0.3070 \\
\hline & Std. Dev. & 0.1122 \\
\hline Small-cap & Mean & 0.1382 \\
\hline & Std. Dev. & 0.1027 \\
\hline
\end{tabular}

F Stat $=11.850, \mathrm{p}=0.0000$

Table 4: foreign exchange exposure for the year 2011-12

\begin{tabular}{|l|l|c|}
\hline Large-cap & Mean & 0.4063 \\
\hline & Std. Dev. & 0.1370 \\
\hline Medium-cap & Mean & 0.2223 \\
\hline & Std. Dev. & 0.1131 \\
\hline Small-cap & Mean & 0.1421 \\
\hline & Std. Dev. & 0.1030
\end{tabular}

F Stat $=13.546, \mathrm{p}=0.0000$

The foreign exchange exposure was found to be lowest for smallcap IT companies, moderate for mid-cap IT companies, and highest 
for large-cap IT companies, significantly across the research period. Clearly, this reflects the operational scale of the capitalization groups.

The trend in foreign exchange exposure in each capitalization group is presented in Table 5.

Table 5: foreign exchange exposure vs. capitalization and years

\begin{tabular}{|c|c|c|c|}
\hline \multirow[t]{8}{*}{ large-cap } & \multirow[t]{2}{*}{$2009-10$} & Mean & 0.4377 \\
\hline & & Std. Dev. & 0.1344 \\
\hline & \multirow[t]{2}{*}{ 2010-11 } & Mean & 0.3964 \\
\hline & & Std. Dev. & 0.1451 \\
\hline & \multirow[t]{2}{*}{ 2011-12 } & Mean & 0.4063 \\
\hline & & Std. Dev. & 0.1370 \\
\hline & \multirow[t]{2}{*}{ Overall } & Mean & 0.4135 \\
\hline & & Std. Dev. & 0.1357 \\
\hline \multirow[t]{8}{*}{ mid-cap } & \multirow[t]{2}{*}{$2009-10$} & Mean & 0.3220 \\
\hline & & Std. Dev. & 0.0862 \\
\hline & \multirow[t]{2}{*}{ 2010-11 } & Mean & 0.3070 \\
\hline & & Std. Dev. & 0.1122 \\
\hline & \multirow[t]{2}{*}{ 2011-12 } & Mean & 0.2223 \\
\hline & & Std. Dev. & 0.1131 \\
\hline & \multirow[t]{2}{*}{ Overall } & Mean & 0.2837 \\
\hline & & Std. Dev. & 0.1100 \\
\hline \multirow[t]{8}{*}{ small--cap } & \multirow[t]{2}{*}{$2009-10$} & Mean & 0.2017 \\
\hline & & Std. Dev. & 0.1928 \\
\hline & \multirow[t]{2}{*}{$2010-11$} & Mean & 0.1382 \\
\hline & & Std. Dev. & 0.1027 \\
\hline & \multirow[t]{2}{*}{ 2011-12 } & Mean & 0.1421 \\
\hline & & Std. Dev. & 0.1030 \\
\hline & \multirow[t]{2}{*}{ Overall } & Mean & 0.1607 \\
\hline & & Std. Dev. & 0.1378 \\
\hline
\end{tabular}

The foreign exchange exposure was found to be lowest for largecap and small-cap IT companies in the year 2010-11 (significantly lower than in 2009-10), while the foreign exchange exposure for mid-cap IT companies decreased further in 2011-12. Also, it was found that small-cap IT companies showed higher variability in foreign exchange exposure than mid-cap and large-cap IT companies. 
The results of the dummy variable regressions are presented in Tables 6 and 7 below.

Table 6: dummy variable regressions for Adjusted Profit After Tax Margin (APATM)

\begin{tabular}{|l|l|l|l|l|}
\hline & model I & model II & model III & $\begin{array}{l}\text { model } \\
\text { IV }\end{array}$ \\
\hline (Constant) & $0.1656^{* *}$ & $0.1505^{* *}$ & $0.1688^{* *}$ & $0.1529^{* *}$ \\
\hline FE Exposure & -0.0820 & -0.0335 & -0.0949 & -0.0440 \\
\hline $2010-11$ & -0.0334 & -0.0143 & -0.0335 & -0.0141 \\
\hline $2011-12$ & -0.0648 & -0.0439 & -0.0677 & -0.0445 \\
\hline mid-cap & 0.0527 & 0.0512 & $0.0608^{* *}$ & $0.0597^{*}$ \\
\hline large-cap & $0.0955^{*}$ & $0.0972^{*}$ & $0.0787^{* *}$ & $0.0773^{* *}$ \\
\hline FE Exposure*mid-cap & 0.0257 & 0.0277 & & \\
\hline FE Exposure*large-cap & -0.0467 & -0.0542 & & \\
\hline FE Exposure*2010-11 & 0.0597 & & 0.0601 & \\
\hline FE Exposure*2011-12 & 0.0651 & & 0.0727 & \\
\hline$R^{2}$ & 0.1450 & 0.1420 & 0.1434 & 0.1400 \\
\hline F Stat & 1.5080 & 1.9440 & 1.9615 & $2.7380^{*}$ \\
\hline p-value & 0.1590 & 0.0730 & 0.0700 & 0.0240 \\
\hline
\end{tabular}

The results of the dummy variable regressions for Adjusted Profit After Tax Margin (APATM) were inconclusive, with model IV explaining $14.0 \%$ of the variation in APATM and attaining statistical significance, whereas models I - III with interactions included failing to attain statistical significance. Thus, the interactions can be ignored, and model IV suggests no significant impact of foreign exchange exposure on APATM, and significant differences between small-cap and mid- and large-cap IT firms in APATM. 
Table7: dummy variable regressions for Return on Capital Employed (ROCE)

\begin{tabular}{|l|c|c|c|c|}
\hline & model I & model II & model III & model IV \\
\hline (Constant) & $0.2116^{* *}$ & $0.1977^{* *}$ & $0.1763^{* *}$ & $0.1702^{* *}$ \\
\hline FE Exposure & $-0.2189^{*}$ & $-0.1715^{*}$ & -0.0538 & -0.0381 \\
\hline $2010-11$ & -0.0262 & -0.0146 & -0.0326 & -0.0156 \\
\hline $2011-12$ & -0.0281 & -0.0060 & -0.0118 & -0.0096 \\
\hline mid-cap & 0.0230 & 0.0218 & $0.0539^{*}$ & $0.0553^{*}$ \\
\hline large-cap & -0.0110 & -0.0085 & $0.1373^{* *}$ & $0.1387^{* *}$ \\
\hline FE Exposure*mid-cap & 0.1516 & 0.1490 & & \\
\hline FE Exposure*large-cap & $0.4393^{* *}$ & $0.4261^{* *}$ & & \\
\hline FE Exposure*2010-11 & 0.0344 & & 0.0564 & \\
\hline FE Exposure*2011-12 & 0.0701 & & 0.0056 & \\
\hline $\mathrm{R}^{2}$ & 0.2460 & 0.2450 & 0.1920 & 0.1910 \\
\hline F Stat & $2.9039^{* *}$ & $3.7940^{* *}$ & $2.7880^{*}$ & $3.9720^{* *}$ \\
\hline p-value & 0.0050 & 0.0010 & 0.0120 & 0.0030 \\
\hline
\end{tabular}

The results of the dummy variable regressions for Return on Capital Employed (ROCE) were more interesting, with all of the models I - IV attaining statistical significance. Models IV and III suggest no significant impact of foreign exchange exposure on ROCE, and significant differences between small-cap and mid- and large-cap IT firms in ROCE, and no significant interactions between capitalization groups and years/trend. However, model II suggests significant negative impact of foreign exchange exposure on ROCE, and significant positive interaction of foreign exchange exposure and large-cap on ROCE, explaining $24.5 \%$ of the variation in ROCE, and attaining statistical significance, and this is reinforced in model I, with no significant interactions between capitalization groups and years/trend.

\section{Discussion}

The results of the study indicate a negative impact of foreign exchange exposure on profitability, with positive impact for largecap IT firms. Thus, downward movements in the exchange rate would benefit small- and mid-cap IT firms but would adversely affect large-cap firms, and vice versa for upward movements. This is clearly a short-run phenomenon. Thus, small- and mid-cap IT 
firms should hedge against a rise in exchange rates in the short run, while large-cap firms should hedge against a fall in exchange rates in the short run.

Also, IT firms should continuously monitor their foreign exchange exposure for contingency planning, especially when exchange rates are very volatile. Though the results of the study indicate that most IT firms have low to moderate foreign exchange exposure, so that the impact of exchange rate fluctuations would not be expected to be severe, it is better for firms to carefully monitor foreign exchange trends and take appropriate steps in case of high volatility in exchange rates. Large IT companies in particular should undertake hedging in order to reduce their foreign exchange exposure levels. Also, companies may consider routing payments through subsidiary companies in order to eliminate transaction exposure.

The results of the study are in contrast to those of Dash and Madhava (2009). The high foreign exchange exposure of a small segment of small-cap IT firms was not evidenced in the current study, perhaps due to insolvency or suspension of operations. This suggests that foreign exchange exposure may be a predictor for financial distress for small-cap IT firms.

Another observation with respect to the results of Dash and Madhava (2009) is that the foreign exchange exposure has decreased overall in 2009-12 as against 2005-07. This is probably the fallout of the global financial crisis of 2008-09, as well as subsequent Euro-zone crises. In fact, due to the spells of high volatility in exchange rates in 2007, most large IT firms have adopted foreign exchange hedging strategies such as forwards and options in the short-run and currency swaps in the long-run (Dash, 2009). Further, changes in the US outsourcing policies under the Obama administration post-global financial crisis have forced IT firms to shift to markets other than the US, particularly Europe and Asia, and the domestic market, thereby reducing their foreign exchange exposure.

\section{Limitations}

There are some limitations inherent in the present study. The sample size taken for study is small; hence it may not be possible to 
generalize the results of the study to all IT firms. Also, the study is based on the Bodnar-Marston (2002) model, which is of limited use, for example, if the company is exposed to several different currencies. There is great scope to develop a more comprehensive framework, incorporating measures of multiple sources of risk would be more appropriate for understanding risk management in IT companies. There is scope for more rigorous study along these lines. Also, further study can examine foreign exchange exposure in other sectors, for example, comparing product-based industries with service-based industries.

\section{References}

Allayannis, G., (1997) The time-variation of the exchange-rate exposure: an industry analysis, Darden School Working Paper, University of Virginia, DSWP \# 97- 29.

Amihud, Y. (1994) Exchange rates and the valuation of equity shares, in Amihud, Y. \& Levich, R. (Eds), Exchange Rates and Corporate Performance, Irwin, New York, 49-59.

Bodnar, G. M. \& Gentry, W. M. (1993). Exchange rate exposure and industry characteristics: Evidence from Canada, Japan, and the USA. Journal of International Money and Finance, 12(1) 29-45.

Bodnar, G. M. \& Marston, R. C. (2002). Exchange rate exposure: A simple model. in J. Jay Choi, Michael R. Powers (Eds.) Global Risk Management: Financial, Operational, and Insurance Strategies (International Finance Review 3), Emerald Group Publishing Limited, 107-115.

Choi, J. J. \& Prasad, A. (1995). exchange risk sensitivity and its determinants: A firm and industry analysis of US multinationals. Financial Management, 24(3), 77-88.

Dash, M. (2009). Forex risk management strategies for Indian IT companies. SSRN Working Papers, Retrieved from SSRN: http://ssrn.com/abstract $=1473459$.

Dash, M. \& Madhava, A. (2009). A Study on the impact of currency fluctuation on the Indian IT sector. SSRN Working Papers, Retrieved from SSRN: http:/ / ssrn.com/abstract=1326506.

Dhasmana, A. (2013). Operational currency mismatch and firm level performance: Evidence from India. MPRA Working Paper, No. 47935. 
El-Masry, A., Abdel-Salam, O. \& Alatraby, A. (2007). The exchange rate exposure of UK non-financial companies. Managerial Finance, 33(9), $620-641$.

Griffin, J.M. \& Stulz, R. (2001). International competition and exchange rate shocks: Cross- country industry analysis of stock returns. Review of Financial Studies, 14, 215-241.

Hyde, S. (2007). The response of industry stock returns to market, exchange rate and interest rate risks. Managerial Finance, 33(9), 693709.

Jorion, P. (1990). The exchange-rate exposure of U.S. multinationals. Journal of Business, 331-345.

Salifu, Z., Osei, K. A., \& Adjasi, C. K. D. (2007). Foreign exchange risk exposure of listed companies in Ghana. The Journal of Risk Finance, $8(4), 380-393$. 